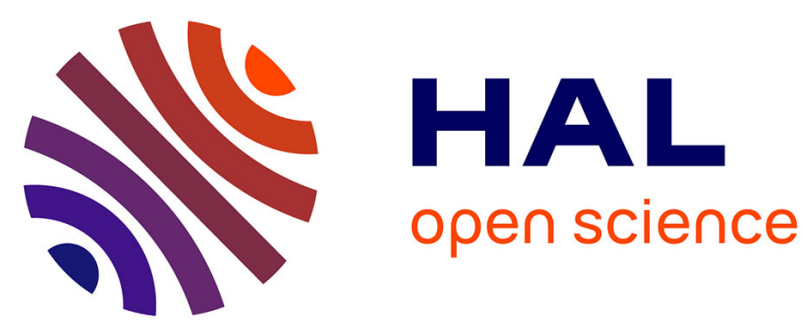

\title{
Determination of Local Thermophysical Properties and Heat of Transition from Thermal Fields Measurement During Drop Calorimetric Experiment
}

\author{
Vincent Delobelle, Denis Favier, Hervé Louche, Nathanael Connesson
}

\section{- To cite this version:}

Vincent Delobelle, Denis Favier, Hervé Louche, Nathanael Connesson. Determination of Local Thermophysical Properties and Heat of Transition from Thermal Fields Measurement During Drop Calorimetric Experiment. Experimental Mechanics, 2015, 55 (4), pp.711-723. 10.1007/s11340-014-9877-z . hal-01300519

\author{
HAL Id: hal-01300519 \\ https://hal.science/hal-01300519
}

Submitted on 11 Apr 2016

HAL is a multi-disciplinary open access archive for the deposit and dissemination of scientific research documents, whether they are published or not. The documents may come from teaching and research institutions in France or abroad, or from public or private research centers.
L'archive ouverte pluridisciplinaire HAL, est destinée au dépôt et à la diffusion de documents scientifiques de niveau recherche, publiés ou non, émanant des établissements d'enseignement et de recherche français ou étrangers, des laboratoires publics ou privés. 


\title{
Determination of local thermophysical properties and heat of transition from thermal fields measurement during drop calorimetric experiment
}

\author{
V. Delobelle ${ }^{\mathrm{a}}$, D. Favier ${ }^{*, a}$, H. Louche ${ }^{\mathrm{b}}$, N. Connesson ${ }^{\mathrm{a}}$ \\ ${ }^{a}$ Université de Grenoble/CNRS, TIMC-IMAG UMR 5525, Grenoble, France \\ ${ }^{b}$ Laboratoire de Mécanique et de Génie Civil (LMGC), Université de Montpellier 2, \\ CNRS, CC048, Place E. Bataillon, 34095 Montpellier Cedex, France
}

\begin{abstract}
This paper proposes a non-contact original method to estimate local thermophysical properties (heat capacity and thermal conductivity) and heats of transition from plane thin specimens. This method is based on measurement of temperature fields with an infrared camera during a drop calorimetric experiment. A studied specimen and a reference specimen, with similar geometries, are simultaneously tested. Firstly, the method is validated by estimating heat capacity and thermal conductivity of Vanadium specimens and by comparing the determined values with those obtained by Differential Scanning Calorimetry and by a laser flash method, respectively. Secondly, the method is used to determine latent heats of martensitic transformations. These heats of transition are determined during homogeneous and heterogeneous drop calorimetric experiments of NiTi shape memory alloys specimens. Measured transformation temperatures and latent heats are in good accor-
\end{abstract}

\footnotetext{
*Corresponding author, Denis.Favier@imag.fr, Tel:+33456520088 Fax +33476 768 844
} 
dance with results obtained by Differential Scanning Calorimetry.

Key words: Infrared thermography, heat capacity, thermal conductivity, heat sources estimation, experimental benchmark, NiTi Shape Memory

Alloy

\section{Introduction}

2 Knowledge of heat capacity and thermal conductivity of materials is of 3 crucial importance to model heat exchanges in materials. Heat capacity of 4 materials can be measured with adiabatic calorimeter, Differential Scanning

5 Calorimetry (DSC) [1], modulated DSC [2, 3], dynamic DSC [4], etc. Ma6 terials thermal conductivity is generally measured using a hot wire method 7 [5], the derived hot strip method, a laser flash method [6] or a $3 \omega$ method 8 [7]. Heat of transition is generally measured by DSC [8] or Differential Ther9 mal Analysis. All these classical techniques allow a global measurement of the desired property at the specimen scale. However, in some cases, a local 1 measurement of these properties would be useful, for example in the case 12 of heterogeneous specimens [9] or graded material [10, 11]. The method proposed in this paper allows to locally estimate heat capacity, thermal conductivity and heat of transition from a thin plate specimen. The method has been validated in this paper for homogeneous specimen although it could also be applied to heterogeneous specimen. In such a case, a field of heat capacity, thermal conductivity and heat of transition could be determined.

Infrared measurements are increasingly used. In order to estimate temperature fields on the specimens surface, emissivity property is classically controlled using high emissivity paint on the specimen surface. Heat sources 
estimations based on these temperature fields were proposed in [12, 13]. These estimations were used to study several mechanical coupled problems such as Lüders bands and necking in steels [12, 14], fatigue of materials $[15,16,17,18]$, plasticity in Al olygocrystal [19], thermomechanical behaviour of NiTi Shape Memory Alloys (SMA) [13, 20, 21, 22, 23], etc.

In this paper, an original method, called Thermal Field Measurement (TFM) method, is proposed. This non-contact method allows to estimate thermophysical properties of material and heat of transition locally while classical methods are global. This method is based on the observation with an infrared camera of the natural cooling of two specimens (one being the 'reference' while the other is 'studied').

In the first section, the TFM models and method are presented. Heat diffusion models, method principle, and the methods to estimate heat capacity, thermal conductivity and heat of transition are successively proposed.

The second section is an experimental validation. First, experimental setup, materials and data processing are presented. Then, heat capacity of Vanadium $C_{V a}$ was estimated using TFM method and DSC. Results are successfully compared. Then, Vanadium thermal conductivity $k_{V a}$ was estimated using TFM method. Results are compared to those obtained with the laser flash method. Finally, heat of transition of NiTi SMAs was estimated in a homogeneous and heterogeneous case with the TFM method. Results are successfully compared to those obtained by DSC, which is the standard method to determine characteristic temperatures and heat of the martensitic transformations occurring in this material [24]. 


\section{Thermal Field Measurement Models and Methods}

\subsection{Heat diffusion models}

In this part, the heat diffusion models used in the following are presented. The general 3D heat diffusion equation linking temperature $T(x, y, z, t)$ and heat sources $s(x, y, z, t)$ at a spatial point located in $(x, y, z)$ at current time $t$, is expressed in the following form:

$$
\rho C \frac{\partial T}{\partial t}-k \operatorname{lap}(T)=s=\rho \dot{q},
$$

where $\rho$ is the mass density, $C$ the heat capacity, $k$ the thermal conductivity of the material and lap stands for the laplacian operator. In the right hand side of this equation, $s$ is the volumic heat sources $\left(W m^{-3}\right)$ and $\dot{q}=\frac{s}{\rho}$ represents the massic heat sources in the material $\left(W \mathrm{~kg}^{-1}\right)$.

Figure 1 shows the specimens used in the present paper. The two sides of the sample (1) of thickness $e_{1}$ are coated with a high emissivity paint (p) of thickness $e_{P}$. The properties of the material or paint are the mass density $\rho_{i}$, thermal conductivity $k_{i}$, heat capacity $C_{i}$ and volumic heat sources $s_{i}$ where $i$ indexes the material $(i=1)$ or the paint $(i=p)$. The two paint layers are supposed identical (properties and thickness).

In order to take into account the two paint layers presented in Fig. 1, the plate is considered as a sandwich material. Mathematical developments to write models presented below are fully explained in $[12,13]$ in the case of an homogeneous plate in the thickness. Identical development can be done in the case of a sandwich material, as explained in [33, 35].

A first model is obtained for thin plane sandwich specimen. Integrating equation 1 in the specimen thickness ( $\mathrm{z}$ in Figure 1 ) provides the following 
2D model:

$$
\frac{2 e_{p} \rho_{p} C_{p}+e_{1} \rho_{1} C_{1}}{e_{1}} \frac{\partial \widetilde{T}}{\partial t}-\frac{2 e_{p} k_{p}+e_{1} k_{1}}{e_{1}} \operatorname{lap}_{2 D}(\widetilde{T})+\frac{f}{e_{1}}=\widetilde{s_{1}},
$$

where $\widetilde{T}=\widetilde{T}(x, y, t)$ is the averaged temperature in the thickness of the specimen and $\operatorname{lap}_{2 D}(\widetilde{T})=\frac{\partial^{2} \widetilde{T}}{\partial x^{2}}+\frac{\partial^{2} \widetilde{T}}{\partial y^{2}}$. In equation $2, \widetilde{s_{1}}$ represents the volumic heat sources $\left(W \mathrm{~m}^{-3}\right)$ in the specimen. Heat sources in the paint are supposed null $\left(s_{p}=0\right)$. The function $f$ models heat losses from the lateral surfaces by radiation $f_{\text {rad }}$ and convection $f_{\text {conv }}$, leading to the following expression:

$$
f(x, y, \widetilde{T})=\underbrace{2 \epsilon \sigma\left(\widetilde{T^{4}}-T_{0}^{4}\right)}_{f_{\text {rad }}}+\underbrace{2 h\left(\widetilde{T}-T_{0}\right)}_{f_{\text {conv }}},
$$

where $T_{0}$ is the ambient temperature, $\epsilon$ the paint layer emissivity, $\sigma$ the Stephan-Boltzman constant, and $h$ is the convection coefficient. As shown in equation 3 , this function $f(x, y, \widetilde{T})$ is independent on the material. A second model can be obtained to study the case of uniaxial heterogeneous thermal field, for exemple for slender thin plane specimen. Assuming a quasihomogeneous field in the transverse direction, equation 2 can be integrated in the transverse direction (y in Figure 1) which allows to write the 1D model:

$$
\frac{2 e_{p} \rho_{p} C_{p}+e_{1} \rho_{1} C_{1}}{e_{1}} \frac{\partial \widetilde{\widetilde{T}}}{\partial t}-\frac{2 e_{p} k_{p}+e_{1} k_{1}}{e_{1}} \operatorname{lap}_{1 D}(\widetilde{\widetilde{T}})+\frac{f}{e_{1}}=\widetilde{\widetilde{s_{1}}},
$$

where $\widetilde{\widetilde{T}}=\widetilde{\widetilde{T}}(x, t)$ is the average of $\widetilde{T}$ in the transverse direction of the specimen and $\operatorname{lap}_{1 D}(\widetilde{\widetilde{T}})=\frac{\partial^{2} \widetilde{\widetilde{T}}}{\partial x^{2}}$. In that case the heat losses function is written:

$$
f(x, \widetilde{\widetilde{T}})=\underbrace{2 \epsilon \sigma\left(\widetilde{\widetilde{T}}{ }^{4}-T_{0}^{4}\right)}_{f_{\text {rad }}}+\underbrace{2 h\left(\widetilde{\widetilde{T}}-T_{0}\right)}_{f_{\text {conv }}},
$$


Finally, a third model can be obtained in the case of uniform temperature. Integrating equation 4 in the axial direction provides the 0D model:

$$
\frac{2 e_{p} \rho_{p} C_{p}+e_{1} \rho_{1} C_{1}}{e_{1}} \frac{d \widetilde{\widetilde{T}}}{d t}+\frac{f}{e_{1}}=\underset{\widetilde{s_{1}}}{ },
$$

85 86

where $\widetilde{\widetilde{T}}=\widetilde{\widetilde{T}}(t)$ is the temperature average of $T(x, y, z, t)$. The heat losses function is written:

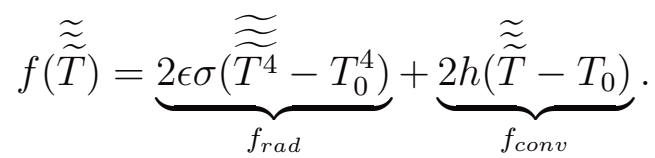

These 2D, 1D and 0D model will be used to analyze the temperature fields variation versus time during different drop calorimetric experiments.

\subsection{TFM Method principle}

All the experiments are based on the observation of the simultaneous natural cooling in the same environment of two specimens, referred to as 'studied' (s) and 'reference' (r) specimen (Figure 2). The thermal capacity and conductivity of the 'reference' specimen are known. Furthermore, no transformation within the 'reference' specimen occurs in the temperature range $\left(\widetilde{s}_{1}=\widetilde{\widetilde{s}}_{1}=\widetilde{\widetilde{s}}_{1}=0\right)$.

During the experiments, the 'studied' and 'reference' specimens are located in the same thermal environment. The two specimens are painted with an identical high emissivity paint $\left(\epsilon_{r}=\epsilon_{s}=\epsilon\right)$. Thus:

- The radiation part $f_{r a d}$ of the heat losses function $f$ is identical for both specimens and is only function of the temperature (equations (3), (5) and (7)). 
- The second part of the heat losses function $f_{\text {conv }}$ is due to convection. The heat transfer coefficient $h$ is dependent on the heat transfer mode, the flow regime, etc: the heat transfer coefficient $h$ may depend on the local convection mode:

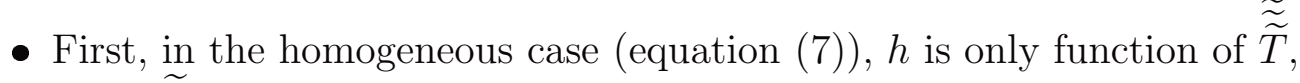
i.e. $h(\underset{\widetilde{T}}{\widetilde{\sigma}})$.

- Second, in the $1 \mathrm{D}$ case (equation (5)), $h$ is only function of $\widetilde{\widetilde{T}}$ and $x$, i.e. $h(\widetilde{T}, x)$.

- Last in the $2 \mathrm{D}$ case (equation (3)), $h$ is function of $\widetilde{T}$, $\mathrm{x}$, and $\mathrm{y}$, i.e. $h(\widetilde{T}, x, y)$.

The 'studied' and 'reference' specimens being in the same environment, the heat losses functions (3), (5) and (7) are assumed identical for the two specimens.

For the 'reference' specimen, heat sources are zero during all the experiments. Thus this specimen is used to estimate the local heat losses function $f$ from equations (2), (4) and (6) applied to the 'reference' thermal fields measured during the drop calorimetric experiment. Then, the local heat losses function $f$ is used in different configurations to estimate the local heat capacity (section 2.3), thermal conductivity (section 2.4) and heat of transition (section 2.5) of the 'studied' specimen.

\subsection{Estimation of heat capacity $C$ for homogeneous samples}

For homogeneous sample, estimation of heat capacity $C$ is performed while observing simultaneous uniform temperature cooling of the studied 
132

and reference specimens (Figure 2.a). During the experiment, the specimen surface temperature fields $T_{s}$ and $T_{r}$ of 'studied' and 'reference' specimens, respectively, are measured and the temperature field homogeneities are checked experimentally. The materials and experimental temperature range are chosen so that no phase change occurs in the materials during the experiment; heat sources $s$ are zero. Thus, the 0D thermal model (equation (6)) applied to each of the two specimens provides the equations:

$$
\begin{gathered}
\left(\rho_{s} C_{s} e_{s}+2 \rho_{p} C_{p} e_{p}\right) \frac{d \widetilde{\widetilde{T}}_{s}}{d t}=-f\left(\widetilde{\widetilde{T}}_{s}\right), \\
\left(\rho_{r} C_{r} e_{r}+2 \rho_{p} C_{p} e_{p}\right) \frac{d \widetilde{\widetilde{T}}_{r}}{d t}=-f\left(\widetilde{\widetilde{T}}_{r}\right) .
\end{gathered}
$$
for capar

\footnotetext{
The reference thermophysical properties being known and $\widetilde{\widetilde{T}}_{r}$ being measured, $f(\underset{\widetilde{T}}{\widetilde{\widetilde{T}}})$ can be computed using equation $(9)$ and the estimation of $\frac{\partial \widetilde{\widetilde{T_{r}}}}{\partial t}$ from experimental cooling curve of the reference specimen.

Furthermore, when ${\underset{\widetilde{T}}{s}}_{=}=\underset{\widetilde{T}_{r}}{\approx} \underset{\widetilde{T}}{\widetilde{\widetilde{T}}}$, the heat losses function $f(\widetilde{\widetilde{T}})$ is identical for both 'reference' and 'studied' specimens and the studied specimen heat apacity $C_{s}$ can be computed by:
}

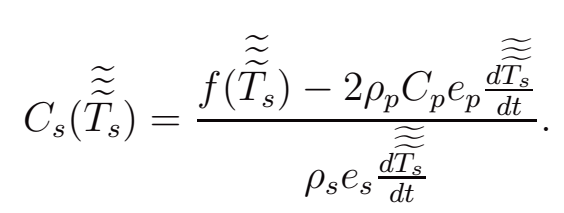

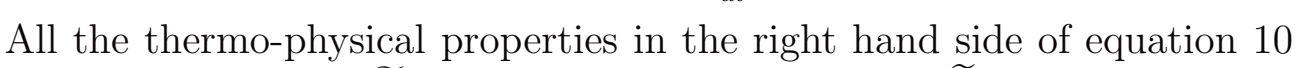
are known. The term $\frac{d \underset{\widetilde{T_{s}}}{d t}}{\approx}$ is estimated at temperature $\underset{\widetilde{\widetilde{T}}}{\widetilde{\widetilde{T}}}$ from the experimental cooling curve of the studied specimen. 


\subsection{Estimation of thermal conductivity $k$}

Using the experimental setup proposed in Figure 2.b, axially heterogeneous (1D) temperature fields are obtained during cooling and are used to estimate the thermal conductivity $k$. Once again for that experiment, the material and temperature range are chosen so that no transition occurs during the experiment; so heat sources are zero. Applying equation (4) to each of the two specimens, and considering hypotheses previously described, it can be written:

$$
\begin{gathered}
\left(\rho_{s} C_{s} e_{s}+2 \rho_{p} C_{p} e_{p}\right) \frac{\partial \widetilde{\widetilde{T}}_{s}}{\partial t}-\left(k_{s} e_{s}+2 k_{p} e_{p}\right) \frac{\partial^{2} \widetilde{\widetilde{T}}_{s}}{\partial x^{2}}=-f\left(x_{s}, \widetilde{\widetilde{T}}_{s}\right), \\
\left(\rho_{r} C_{r} e_{r}+2 \rho_{p} C_{p} e_{p}\right) \frac{\partial \widetilde{\widetilde{T}}_{r}}{\partial t}-\left(k_{r} e_{r}+2 k_{p} e_{p}\right) \frac{\partial^{2} \widetilde{\widetilde{T}}_{r}}{\partial x^{2}}=-f\left(x_{r}, \widetilde{\widetilde{T}}_{r}\right) .
\end{gathered}
$$

In these equations, only $f$ and $k_{s}$ are unknown. $f(x, \widetilde{\widetilde{T}})$ can be estimated thanks to equation 12 and the experimental data for the reference specimen. From these data, the terms $\frac{\partial \widetilde{\widehat{T}_{r}}}{\partial t}$ and $\frac{\partial^{2} \widetilde{\widetilde{T}_{r}}}{\partial x^{2}}$ are estimated for every position $x$ and temperature $T$. At the position $x_{s}=x_{r}=x$ from the mass, and at the temperature $\widetilde{\widetilde{T}}_{s}=\widetilde{\widetilde{T}}_{r}=\widetilde{\widetilde{T}}$, the studied specimen thermal conductivity $k_{s}$ can thus be determined:

$$
k_{s}\left(x_{s}, \widetilde{\widetilde{T}}_{s}\right)=\frac{f\left(x_{s}, \widetilde{\widetilde{T}}_{s}\right)+\left(\rho_{s} C_{s} e_{s}+2 \rho_{p} C_{p} e_{p}\right) \frac{\partial \widetilde{\widetilde{T}_{s}}}{\partial t}-2 k_{p} e_{p} \frac{\partial^{2} \widetilde{\widetilde{T}_{s}}}{\partial x^{2}}}{e_{s} \frac{\partial^{2}}{\partial x^{2}}}
$$

155 The term $\frac{\partial \widetilde{T_{s}}}{\partial t}$ is estimated for every position from the 'studied' specimen cooling curves and the term $\frac{\partial^{2} \widetilde{\widetilde{T}_{s}}}{\partial x^{2}}$ is estimated for every temperature from 
the 'studied' specimen thermal profiles. All the thermo-physical properties in the right hand side of equation 13 are known.

\subsection{Estimation of local heat of transition}

The reference and studied materials and temperature range are chosen in this experiment so that:

- no phase change occurs in the 'reference' specimen,

- phase change occurs in the 'studied' specimen.

Heat of transition is estimated using the experimental set-up proposed in Figure 2.a (homogeneous cooling) or Figure 2.b (heterogeneous 1D cooling).

\subsubsection{Homogeneous (OD) cooling}

Homogeneous (0D) temperature fields are obtained during cooling. Equation 6 applied to the 'studied' and 'reference' specimens provides two equations:

$$
\begin{gathered}
\frac{\left(\rho_{s} C_{s} e_{s}+2 \rho_{P} C_{P} e_{P}\right)}{e_{s}} \frac{d \widetilde{\widetilde{T}}_{s}}{d t}=\rho_{s} \underset{\dot{\tilde{q}}_{s}}{\approx}-f\left(\widetilde{\widetilde{T}}_{s}\right), \\
\left(\rho_{r} C_{r} e_{r}+2 \rho_{P} C_{P} e_{P}\right) \frac{d \widetilde{\widetilde{T}}_{r}}{d t}=-f\left(\widetilde{\widetilde{T}}_{r}\right) .
\end{gathered}
$$

$170 \quad$ Again, the heat losses function $f(\underset{\widetilde{T}}{\widetilde{\widetilde{T}}})$ is identical for 'reference' and 'stud171 ied' specimens. $f(\widetilde{\widetilde{T}})$ is estimated from equation 15 . 
Thus, at the temperature $\widetilde{\widetilde{T}}_{s}$, the studied specimen heat source can be computed by:

$$
\underset{\widetilde{\widetilde{q}}_{s}}{\approx}\left(\widetilde{\widetilde{T}}_{s}\right)=\frac{\left(\rho_{s} C_{s} e_{s}+2 \rho_{P} C_{P} e_{P}\right)}{e_{s} \rho_{s}} \frac{\partial \widetilde{\widetilde{T}}_{s}}{\partial t}+\frac{f\left(\widetilde{\widetilde{T}}_{s}\right)}{e_{s} \rho_{s}} .
$$

\subsubsection{Axially heterogeneous (1D) cooling}

Using the experimental setup proposed in Figure 2.b, heterogeneous (1D) temperature fields are obtained. In that case equation 4 applied to each of the two specimens provides two equations:

$$
\begin{gathered}
\frac{\left(\rho_{s} C_{s} e_{s}+2 \rho_{P} C_{P} e_{P}\right)}{e_{s}} \frac{\partial \widetilde{\widetilde{T}}_{s}}{\partial t}-\frac{\left(k_{s} e_{s}+2 k_{P} e_{P}\right)}{e_{s}} \frac{\partial^{2} \widetilde{\widetilde{T}}_{s}}{\partial x^{2}}=\rho_{s} \widetilde{\widetilde{q}}_{s}-\frac{f\left(x_{s}, \widetilde{\widetilde{T}}_{s}\right)}{e_{s}}, \\
\left(\rho_{r} C_{r} e_{r}+2 \rho_{P} C_{P} e_{P}\right) \frac{\partial \widetilde{\widetilde{T}}_{r}}{\partial t}-\left(k_{r} e_{r}+2 k_{P} e_{P}\right) \frac{\partial^{2} \widetilde{\widetilde{T}}_{r}}{\partial x^{2}}=-f\left(x_{r}, \widetilde{\widetilde{T}}_{r}\right) .
\end{gathered}
$$

Equation 18 and experimental data for the reference specimen is used to estimate $f(x, \widetilde{\widetilde{T}})$. At the temperature $T=T_{s}=T_{r}$ and at the position $x=x_{s}=x_{r}$, heat sources released by the 'studied' material are:

$$
\widetilde{\widetilde{q}}_{s}\left(x_{s}, \widetilde{\widetilde{T}}_{s}\right)=\underbrace{\frac{\left(\rho_{s} C_{s} e_{s}+2 \rho_{P} C_{P} e_{P}\right)}{e_{s} \rho_{s}} \frac{\partial \widetilde{\widetilde{T}}_{s}}{\partial t}}_{\text {Heat storage term }} \underbrace{-\frac{\left(k_{s} e_{s}+2 k_{P} e_{P}\right)}{e_{s} \rho_{s}} \frac{\partial^{2}}{\partial x^{2}}}_{\text {Conduction term }} \underbrace{+\frac{f\left(x_{s}, \widetilde{T}_{s}\right)}{e_{s} \rho_{s}}}_{\text {Heat losses term }} .
$$

This experiment would be useful for heterogeneous specimen and would allow to determine local heat of transition. 


\section{Experimental validation}

\subsection{Experimental setup}

In this study a SC7600 (Flir) camera was used. The camera works in the IR wavelength $\lambda=3-5 \mu m$ with an InSb detector matrix (15 x 15 $\mu m^{2}$ ) and a resolution of $640 \times 480$ pixels. The accuracy of the camera is $\pm 2^{\circ} \mathrm{C}$ in the concerned temperature range and its thermal resolution is about $0,02^{\circ} \mathrm{C}$. The frame rate was $25 \mathrm{~Hz}$. The industrial camera calibration has been performed with a black body in the range -10 to $300^{\circ} \mathrm{C}$.

All specimens were painted with high emissivity paint measured to be $\epsilon=0,95$. Paint thickness was measured with scanning electron microscope to be $25 \pm 5 \mu \mathrm{m}$. IR transmission through the specimen and reflection of the environment, that can affect the measure, have been neglected.

Temperature measurements of the specimen located in the chamber were performed through a quasi-transparent IR windows in CaF2 (Figure 3). This window offers a transmission coefficient of $\tau=0,92$ in the used wavelength. The two specimens were heated up to a known temperature $T_{i n i}$ using a first hot climatic chamber before being carried into a second cold climatic chamber controlled at a known temperature $T_{0}$. To reduce cooling while carrying the specimens between the two chambers, a specific device was used. The natural cooling of the specimens in this second climatic chamber, from $T_{i n i}$ to $T_{0}$, was observed with the IR camera.

In order to obtain homogeneous (0D) or axially heterogeneous (1D) temperature fields during cooling, two types of specimens and fixing were chosen (Figure 3). In the first case, small specimens were suspended with thin thermal insulator wires in order to obtain uniform temperature in each specimen 
(Figure 3.a). In the second case, slender specimens were used and gripped in a steel block, acting as a thermal mass. This thermal mass initially at temperature $T_{0}$ cooled very slowly and created an axial temperature gradient between the free and gripped extremities in each specimen (Figure 3.b).

Reproducibility and heat losses distributions in time and space were tested. Experiments were realized using for the reference and studied specimens two identical specimens with the same material. In such a case, responses of the two specimens were measured to be identical in the whole range of temperature.

\subsection{Materials}

As explained in the first section, a 'reference' specimen is used to evaluate heat losses functions in equations (9),(12),(15), (18). Pure Titanium, in the form of $0.51 \mathrm{~mm}$ thickness sheet, was selected in our experiments as 'reference' specimen. The thermophysical properties of this material are given in Table 1 as reported in the literature. They were also measured using classical methods. Its heat capacity was measured with a DSC experiment and was estimated to $C_{T i}^{D S C}=530 \pm 30 \mathrm{Jg}^{-1} \mathrm{~K}^{-1}$. This result is in good agreement with the literature values (Table 1). In the following, a value of $C_{T i}=530 \mathrm{Jg}^{-1} \mathrm{~K}^{-1}$ has been used. The thermal diffusivity $\left(\lambda=\frac{k}{\rho C}\right)$ of this Titanium specimen was estimated using a laser flash method [33, 36, 37]. Knowing the heat capacity of the material, the thermal conductivity of Titanium was estimated to $k_{T i}^{l f}=20 \pm 2 \mathrm{Wm}^{-1} \mathrm{~K}^{-1}$. This result is in good agreement with the values of the literature (Table 1). In the following, a value of $k_{T i}=20 \mathrm{Wm}^{-1} \mathrm{~K}^{-1}$ has been used.

The 'studied' specimens were cut either in pure Vanadium rolled plate 


\begin{tabular}{|c|c|c|c|}
\hline Material & $\begin{array}{c}\text { Volumic mass } \\
\rho\left(k g m^{-3}\right)\end{array}$ & $\begin{array}{c}\text { Specific heat } \\
C\left(J k^{-1} K^{-1}\right)\end{array}$ & $\begin{array}{c}\text { Thermal conductivity } \\
k\left(W m^{-1} K^{-1}\right)\end{array}$ \\
\hline $\mathrm{Ti}[25,26,27,28,29]$ & 4510 & $520-555$ & $17-22$ \\
\hline $\mathrm{Va}[25,26,27,30]$ & 6000 & $480-505$ & $28-36$ \\
\hline $\mathrm{NiTi}[31,32,33]$ & 6400 & $480-520$ & $9-15$ \\
\hline Paint $[34]$ & 1500 & 1500 & 0.2 \\
\hline
\end{tabular}

Table 1: Thermophysical properties of used materials (literature values). properties of these materials and of the high emissivity paint are given in Table 1 as reported in the literature.

of thickness $0.50 \mathrm{~mm}$ (Sections 3.3 and 3.4) or in a Ti - 50.2 at.\% Ni SMA bright rolled plate of thickness $0.39 \mathrm{~mm}$ (Section 3.5). The thermophysical

Figure 4 shows the DSC of the NiTi SMA selected for the study (section 3.5). This DSC was performed using a DSC TA Q200, with a $10^{\circ} \mathrm{C} \mathrm{min}-1$ heating/cooling rate, with a specimen of $22.9 \mathrm{mg}$ cut with a diamond blade. During cooling, two successive phase transformations were observed:

- from Austenite to R-phase, with $R_{s}=62^{\circ} \mathrm{C}, R_{f}=53^{\circ} \mathrm{C}$ the starting and finishing temperatures, respectively,

- from R-phase to Martensite, with $M_{s}=39^{\circ} \mathrm{C}$ and $M_{f}=12^{\circ} \mathrm{C}$ the starting and finishing temperatures, respectively.

The latent heat released during complete phase transformation, evaluated from the baseline plotted in Figure 4, is equal to $\Delta H_{A-M}=21 \mathrm{Jg}^{-1}$. During heating, a single phase transformation from Martensite to Austenite is 
observed, with starting and finishing transformation temperatures equal to $A_{s}=69^{\circ} \mathrm{C}$ and $A_{f}=84^{\circ} \mathrm{C}$, respectively.

\subsection{Data processing}

Temperatures $T_{s}(x, y, t)$ and $T_{r}(x, y, t)$ measured with the infrared camera on the surface of the samples need to be processed to estimate the desired properties $(C, k$ or $\dot{q})$. The complete data processing flowchart performed with Matlab is presented in Figure 5 for the 1D heterogeneous case.

In the $1 \mathrm{D}$ heterogeneous case, the temperature is supposed homogeneous in the $y$ direction. This assumption was experimentally checked. Thus, temporal averaging in the $y$ direction was estimated and data $\widetilde{\widetilde{T}}_{s}$ and $\widetilde{\widetilde{T}}_{r}$ were obtained. Low pass temporal filtering was then applied to data as reported in $[12,13]$. Then, first derivative terms were estimated by finite difference method and were spatially filtered. To estimate laplacian terms, data $\widetilde{\widetilde{T}}_{s}$ and $\widetilde{\widetilde{T}}_{r}$ were spatially filtered with a polynomial of degree 4 . Knowing the polynomial coefficients, laplacian terms were estimated. This laplacian estimation was studied and checked in [33]. Once the spatial and temporal derivative terms estimated, the heat losses function $f$ and desired property can be estimated using equations presented in section 2. A quasi similar flowchart could be presented in the homogeneous case. Temperatures $T_{s}(x, y, t)$ and $T_{r}(x, y, t)$ were averaged in $x$ and $y$ directions and only the derivative term versus time was estimated.

\subsection{Validation of the TFM heat capacity $C$ measurement}

In this section, the experimental setup proposed in Fig. 3.a and temperatures $T_{i n i}=60^{\circ} \mathrm{C}$ and $T_{0}=0^{\circ} \mathrm{C}$ were chosen (Table 2). The reference 
material was Titanium. The studied material was Vanadium.

\begin{tabular}{|c|c|c|c|c|}
\hline Ref. Mat. & Studied Mat. & Exp. Setup & $T_{i n i}$ & $T_{0}$ \\
\hline $\mathrm{Ti}$ & $\mathrm{Va}$ & Fig. 3.a & $60^{\circ} \mathrm{C}$ & $0^{\circ} \mathrm{C}$ \\
$\mathrm{e}=0.51 \mathrm{~mm}$ & $\mathrm{e}=0.50 \mathrm{~mm}$ & & & \\
\hline
\end{tabular}

Table 2: Information and parameters for TFM heat capacity measurement.

Figure 6.a shows the measured natural cooling curves of the $\mathrm{Ti}$ and $\mathrm{Va}$ specimens. Due to heat losses during the specimens transportation between the heat and cold chambers, the starting temperatures of the two specimens were slightly lower than temperature of the first chamber $T_{i n i}=60^{\circ} \mathrm{C}$. Figure 6.b shows the cooling rate of the two specimens in function of the specimen temperatures (estimated from the cooling curves). During that experiment, cooling rate decreases approximately linearly with the temperature.

Figure 7 shows the Vanadium heat capacity estimated with the TFM method for three experiments in the range 10 to $30^{\circ} \mathrm{C}$ using equation 10 . This range was chosen because filtering process presented in section 3.3 involves edge effects on the estimation of the derivative terms. Moreover, below $10^{\circ} \mathrm{C}$, the denominator of equation 10 is low and induces important noise. Results were obtained using the cooling rates $\left(\frac{d T}{d t}\right)$ presented in Figure 6.b and a constant heat capacity $C_{T i}=530 \mathrm{Jkg}^{-1} \mathrm{~K}^{-1}$.

A constant mean value $C_{V a}^{T F M}=495 \pm 10 \mathrm{Jkg}^{-1} \mathrm{~K}^{-1}$ was determined from these curves. As the $C_{T i}$ is known with an accuracy of $\pm 30 \mathrm{Jg}^{-1} \mathrm{~K}^{-1}$ from the DSC measurement, the Va heat capacity is finally estimated to be $C_{V a}^{T F M}=495 \pm 40 \mathrm{Jkg}^{-1} \mathrm{~K}^{-1}$ with the TFM method. This result is in good agreement with those obtained from DSC on the same material: 
$C_{V a}^{D S C}=480 \pm 40 \mathrm{Jkg}^{-1} \mathrm{~K}^{-1}$ and from literature $C_{V a}^{l i t}=480-505 \mathrm{Jkg}^{-1} \mathrm{~K}^{-1}$, obtained on different Va materials. The method proposed is thus considered experimentally validated. Heat capacity can be estimated with the same accuracy than the DSC method.

\subsection{Validation of the TFM thermal conductivity $k$ measurement}

In this section, the used experimental setup is shown in the Figure 3.b and temperatures $T_{i n i}=60^{\circ} \mathrm{C}$ and $T_{0}=0^{\circ} \mathrm{C}$ were chosen (Table 3). Vanadium was used as the 'studied' material. Titanium was the 'reference' material.

\begin{tabular}{|c|c|c|c|c|}
\hline Ref. Mat. & Studied Mat. & Exp. Setup & $T_{i n i}$ & $T_{0}$ \\
\hline $\mathrm{Ti}$ & $\mathrm{Va}$ & Fig. 3.b & $60^{\circ} \mathrm{C}$ & $0^{\circ} \mathrm{C}$ \\
$\mathrm{e}=0.51 \mathrm{~mm}$ & $\mathrm{e}=0.50 \mathrm{~mm}$ & & & \\
\hline
\end{tabular}

Table 3: Information and parameters for TFM thermal conductivity measurement.

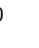

Figure 8 shows the thermal responses of Ti and Va specimens during the 1D experiment. Figure 8.b is the spatio-temporal thermal response of the Ti specimen along the dashed line sketched in Figure 8.a. Figure 8.c shows the temperature temporal evolution of three pixels of $\mathrm{Ti}$ and Va specimens. Figure 8.d shows the axial thermal profiles sketched in Figure 8.a at different times for the $\mathrm{Ti}$ specimen. The specimens cooled during the experiment (Figures 8.b and c), from a quasi-homogeneous temperature to a thermally heterogeneous state with a gradient (Figures 8.b and d) in the specimen main direction. The Ti specimen cooled faster than the Va specimen, as during the 0D experiment (Figure 8.c). Initial temperatures of the two specimens were almost equal (Figure 8.c). At the end of the experiment, the edge close to thermal mass was hotter than the free edge (Figure 8.d). As noted in Table 
1, thermal conductivity of Titanium and Vanadium are different, leading to different heat flux through the specimens. This explains why, at the end of the experiment, the two specimens were not at room temperature $T_{0}$ and that the temperatures were different at a given distance of the thermal mass.

Figure 9 shows the estimated thermal conductivity of the Va specimen, using the equation (13). In this equation, the heat loss function $f(x, \widetilde{\widetilde{T}})$ was estimated from equation 12 and experimental data for the 'reference' specimen. Conductivity values are presented along the axial profile for instants higher than $\mathrm{t}=30 \mathrm{~s}$ in Figure 8.c. For those instants, first derivative terms $\left(\frac{\partial \widetilde{\widetilde{T}}}{\partial t}\right)$ in equations 12 and 13 were negligible compared to the spatial second derivative $\frac{\partial^{2} T}{\partial x^{2}}$. For the two samples, as observed on profiles presented in Fig. 8.d, laplacian term is higher close to steady state. To avoid important edges effect due to spatial filtering, only the central pixels were considered. Using $k_{T i}=20 \mathrm{Wm}^{-1} \mathrm{~K}^{-1}$, a mean thermal conductivity of Vanadium is estimated to be $k_{V a}^{T F M}=37 \mathrm{Wm}^{-1} \mathrm{~K}^{-1}$. Note that this result is in good agreement with literature results (Table 1). Taking into account dispersion of Ti thermal conductivity, heat capacity, and Va heat capacity, Va thermal conductivity is estimated to be $k_{V a}^{T F M}=36 \pm 4 \mathrm{Wm}^{-1} \mathrm{~K}^{-1}$ while it was estimated to be $k_{V a}^{l f}=34 \pm 3 W^{-1} K^{-1}$ with a classical laser flash method and to be $k_{V a}^{l i t}=28-36 W^{-1} K^{-1}$ in the literature. Thus, while estimating thermal conductivities, the accuracy depends on the knowledge of thermophysical properties of the reference material with the TFM method.

\subsection{Validation of the TFM heat of transition measurement}

In this last section, Ti is the 'reference' material and NiTi is the 'studied' specimen. To observe the complete exothermic transformation from Austen- 
ite to Martensite occurring in the NiTi specimen, temperature $T_{i n i}$ had to be above $A_{f}$ and temperature $T_{0}$ below $M_{f}$. In this experiment, the following values were thus chosen: $T_{i n i}=100^{\circ} \mathrm{C}$ and $T_{0}=0^{\circ} \mathrm{C}$.

Experimental results obtained from homogeneous (using device presented in Fig. 3.a) and then from axially heterogeneous (using device presented in Fig. 3.b) cooling are presented and discussed.

\subsubsection{Homogeneous cooling}

Information and parameters chosen for this experiment are given in Table

4. The experimental setup is described in Fig. 3.a.

\begin{tabular}{|c|c|c|c|c|}
\hline Ref. Mat. & Studied Mat. & Exp. Setup & $T_{i n i}$ & $T_{0}$ \\
\hline $\begin{array}{c}\mathrm{Ti} \\
\mathrm{e}=0.51 \mathrm{~mm}\end{array}$ & $\mathrm{e}=0.39 \mathrm{~mm}$ & Fig. 1.a & $100^{\circ} \mathrm{C}$ & $0{ }^{\circ} \mathrm{C}$ \\
\hline
\end{tabular}

Table 4: Information and parameters for TFM heat heat of transition measurement in the homogeneous case.

Figure 10.a shows the temporal evolution of temperature measured in the Ti and NiTi specimens during homogeneous cooling experiment (Figure 3.a).

The Ti temperature decreasing curve obtained for the Ti specimen is exponential like. However, for the NiTi specimen, two bumps due to the two exothermic phase transformations are noted, from Austenite to R-phase and from R-phase to Martensite, successively. The two specimens coolings started and finished to identical temperatures. Figure 10.b shows the cooling rate $\dot{T}$ of Ti and NiTi specimens. The cooling rate range is between -1 and $-8 K s^{-1}$. From these curves and from equations 18 and 19, heat source occurring in the NiTi specimen can be estimated. 
Figure 11.a presents the ratio $\frac{\dot{q}}{|\dot{T}|}$ results for the TFM method using a heat capacity for NiTi specimen equal to $500 \mathrm{Jkg}^{-1} \mathrm{~K}^{-1}[31,32,33]$. DSC curve is also presented in black.

Global shapes of the curves obtained by the two techniques are similar; the amplitude of the peaks by the two methods are in good accordance. Table 5 summarizes the two peak temperatures, respectively noted $T_{A-R}$ and $T_{R-M}$ and the transformation temperature $R_{s}, R_{f}, M_{s}$ and $M_{f}$ for the two techniques (DSC (Figure 4) and TFM 0D): peak and transformation temperatures are almost equal for the two techniques. From these values, starting temperature $R_{s}$ and $M_{s}$ for the two transformations appear to be very close for the two methods. Finishing temperature $R_{f}$ and $M_{f}$ are however lightly higher with the TFM method. Such a difference can partially be explained by thermal inertia effects in the DSC experiment: this inertia leads to underestimate finishing temperature of the transformation with this technique $[33,38]$. With the TFM method, the specimen transforms naturally and independently of the environment; the TFM method exhibits no thermal inertia. Differences in the temperatures may also be due to the accuracy of the IR camera $\left( \pm 2^{\circ} \mathrm{C}\right)$ and of the DSC one.

Eventually, integrating the ratio $\frac{\dot{q}}{|\bar{T}|}$ over temperature allows to estimate the energy released by the material versus temperature:

$$
E=\int_{T_{1}}^{T} \frac{\dot{q}}{|\dot{T}|} d T
$$

Its evolution is plotted versus temperature, for TFM and DSC techniques in Figure 11.b. For the two methods, transformed energy $E$ is estimated between the initial starting temperature $T_{1}=R_{s i}=74^{\circ} \mathrm{C}$ and the cur- 


\begin{tabular}{|c|c|c|c|}
\hline${ }^{\circ} C$ & DSC & TFM 0D & TFM 1D \\
\hline$T_{A-R}$ & 58 & 60 & 59 \\
\hline$T_{R-M}$ & 28 & 32 & 30 \\
\hline$R_{s}$ & 62 & 63 & 62 \\
\hline$R_{f}$ & 53 & 57 & 54 \\
\hline$M_{s}$ & 39 & 39 & 39 \\
\hline$M_{f}$ & 12 & 17 & 19 \\
\hline
\end{tabular}

Table 5: Peaks temperatures and transformation temperatures estimated from DSC, TFM 0D and TFM 1D.

rent temperature. The energy, for the transformation finishing temperature $M_{f e}=12^{\circ} \mathrm{C}$ (see Figure 11.a), corresponding to the latent heat of transition of the material, is estimated to be $19 \mathrm{Jg}^{-1}$ for the TFM method. From the DSC curve, the latent heat of transition is estimated to be $19.5 \mathrm{Jg}^{-1}$, using the baseline plotted in Figure 11.a. The results using the TFM method and DSC are in good agreement.

For the TFM method, the main issue is the knowledge of the thermophysical properties of the material. A similar drawback occurs for the DSC, where the choice of the baseline is the key point to realize quantitative latent heat of transition measurements [23]. The two techniques are however quantitatively in good agreements.

\subsubsection{One dimensional heterogeneous cooling}

Information and parameters chosen for this experiment are given in Table 6 .

Spatio-temporal evolution along an axial profile is plotted for Ti specimen 


\begin{tabular}{|c|c|c|c|c|}
\hline Ref. Mat. & Studied Mat. & Exp. Setup & $T_{i n i}$ & $T_{0}$ \\
\hline $\mathrm{Ti}$ & NiTi & Fig. 1.b & $100^{\circ} \mathrm{C}$ & $0{ }^{\circ} \mathrm{C}$ \\
$\mathrm{e}=0.51 \mathrm{~mm}$ & $\mathrm{e}=0.39 \mathrm{~mm}$ & & & \\
\hline
\end{tabular}

Table 6: Information and parameters for TFM heat of transition measurement in the heterogeneous case.

in Figure 12.a and for NiTi specimen in Figure 12.b during heterogeneous cooling (Figure 3.b). In Figures 12.c.d, temporal evolution of $\mathrm{Ti}$ and $\mathrm{NiTi}$ specimens temperatures are respectively plotted for three pixels (pixel 65, 100 and 150) located at different distances of the thermal mass. At the beginning of the experiment, all points had identical temperature and difference of temperature appeared during cooling. At the end of the experiment, the thermal mass was still hot and conductivity occurred in the specimens: pixels close to the thermal mass were hotter than those close to the free edge (Figures 12.e.f). In the Ti specimen, natural cooling of every pixel was observed, as during the 0D experiment. Additionally for NiTi specimen (Figure 12.d), the two phase transformations from Austenite to R-phase and from R-phase to Martensite can be observed. Figures 12.e.f eventually show the axial thermal profiles of the two specimens at different times. However, for the NiTi specimen, bumps appeared around times $t=10 \mathrm{~s}$ and $\mathrm{t}=20 \mathrm{~s}$ in the thermal profiles due to exothermic phase transformations occurring in the specimen.

The ratio $\frac{\dot{q}}{|\bar{T}|}$ was estimated from $1 \mathrm{D}$ thermal profiles (Figure 13.a), using a heat capacity for NiTi specimen equal to $500 \mathrm{Jkg}^{-1} \mathrm{~K}^{-1}[31,32,33]$ and a thermal conductivity of $11 \mathrm{Wm}^{-1} \mathrm{~K}^{-1}$. Current study [33] shows that thermal conductivity can be considered identical for Austenite and Martensite 
phases. The spatio-temporal evolution of this ratio is plotted in Figure 13.b. The spatio temporal propagation of the two phase transformations, from Austenite to R-phase and from R-phase to Martensite are clearly visible: the transformation started from the bottom (fast cooling) and finished to the top (slow cooling due to thermal mass inertia) of the specimen.

The ratio $\frac{\dot{q}}{|T|}$ calculated with the TFM method is plotted in Figure 13.c, versus specimen temperature, for pixels 65, 100 and 150 in red, blue and green respectively. The ratio $\frac{\dot{q}}{|\vec{T}|}$ obtained with DSC is also plotted. Qualitatively, the ratios estimated for the three pixels are well superimposed. The peak temperatures and the transformation temperatures for the two techniques (DSC and TFM 1D) are given in Table 2. The peaks obtained with the TFM method and with the DSC are in good agreement. As in the homogeneous case, transformation temperatures estimated with the TFM and DSC (Figure 4) methods are in good agreement. As in the homogeneous case, thermal inertia effects are once again observable in the DSC method.

Evolution of the energy released as function of the temperature during the transformation is also plotted in Figure 13.d. It is estimated from TFM technique for considered pixels and from DSC for the baseline presented in Figure 13.c. Evolution of the energy is similar for the two techniques. The latent heat of transition obtained from TFM method is $17.5 \pm 1 \mathrm{Jg}^{-1}$ for all considered pixels and is slightly lower than the one estimated by DSC. This error is partially due to the underestimation of the heat sources with the process used, but also due to some experimental constraints: as explained, the room temperature was $T_{0}=0^{\circ} \mathrm{C}$ (to avoid freezing problems on the window and on the specimen) which is close to $M_{f}$. In the heterogeneous case, 
the final temperature of every pixel is not $T_{0}$ but lightly above, as observed in Figures 12.c.d. Thus, in a part of the specimen, the phase transformation did not occurred totally and released less energy.

However, knowledge of materials thermophysical properties can affect results. Faulkner et al. [39] measured conductivity coefficients equal to $14 \mathrm{Wm}^{-1} \mathrm{~K}^{-1}$ and $28 \mathrm{Wm}^{-1} \mathrm{~K}^{-1}$ for martensite and austenite, respectively. In this study, thermal conductivity of $k_{N i T i}$ was assumed constant $\left(11 \mathrm{Wm}^{-1} \mathrm{~K}^{-1}\right)$ and independent of the considered phase, as measured in [33]. Figure 14 yet shows the evolution with the temperature of the terms involved in the equation 19 to estimate massic heat sources $\dot{q}$ in NiTi sample for pixels 60 to 70 . Red curve shows the heat storage term, the blue one is for conduction in the sample and the green one represents heat losses. Adding these terms leads to the red curve plotted in Figure 13.c. Main terms are linked to the storage one (red) and to heat losses (green). The conduction term (blue) is almost negligible for temperature above $20^{\circ} \mathrm{C}$. Thus, the accuracy of the $k_{N i T i}$ is not important in that study.

The TFM method in an heterogeneous case exhibits yet quantitative results in good agreement with those obtained by DSC. Note that in this study, the chosen material had homogeneous transformation behavior. As the determination of the properties is local, this technique would allow to determine local latent heat of transition even if the material exhibited heterogeneous transformation behavior. 


\section{Conclusion}

Thermal Field Measurement (TFM) method has been developed and used to estimate heat capacity, thermal conductivity and latent heat of transition of materials. Advantages of this original method are (i) the non-contact aspect, measuring temperature with an infrared camera, while others methods are with contacting methods and (ii) the local aspect of the measurement in the heterogeneous case while other method are global. This last point is very interesting in the case of heterogeneous material. (iii) The absence of inertia effect as in DSC measurement.

The experimental setup to perform the measurement was based on the simultaneous observation, with an infrared camera, of the natural cooling of two specimens: a 'reference' and a 'studied' material. Titanium was used as 'reference' specimen to estimate convection and radiation heat losses.

Firstly, Vanadium has been used to validate the method abilities to estimate thermophysical properties. The TFM method has been proved to be able to provide an accurate measurement of heat capacity $C$ and local thermal conductivity $k$ of Vanadium. Results obtained from TFM techniques, classical DSC, laser flash method and literature were in good agreement. Secondly, NiTi specimen was studied and chosen for its exothermic thermally induced phase transformation. Latent heat of transition of this material was estimated during homogeneous and heterogeneous thermal cases. Results obtained with this technique and with DSC are in good agreement. 


\section{References}

[1] E. Illekova, B. Aba, and F.A. Kuhnast. Measurement of accurate specifc heats of metallic glasses by differential scanning calorimetry (DSC). Part 1. Analysis of theroretical principles and accuracies of suggested measurement procedures. Thermochimica Acta, 195:195-209, 1992.

[2] M. Reading, D. Elliott, and V.L. Hill. A new approach to the calorimetric investigation of physical and chemical transitions. Journal of Thermal Analysis, 40:949-955, 1993.

[3] M. Reading, A. Luget, and R. Wilson. Modulated differential scanning calorimetry. Thermochimica Acta, 238:295-307, 1994.

[4] I. Hatta. AC calorimetric aspect of dynamic differential scanning calorimetry. Thermochimica Acta, 272:49-52, 1996.

[5] W.R. Davis, K.D. Maglic, A. Cezairliyan, and V.E. Peketsky. Hotwire method for the measurement of the thermal conductivity of refractory materials. Compendium of thermophysical property measurement methods, 1984 .

[6] W. Parker, R.J. Jenkins, C.P. Butler, and G.L. Abbott. Flash method of determining thermal diffusivity, heat capacity and thermal conductivity. Journal of Applied Physics, 32:1679-1684, 1961.

[7] H. Wang and M. Sen. Analysis of the 3-omega method for the thermal conductivity measurement. International Journal of Heat and Mass Transfer, 52:2102-2109, 2009. 
[8] C. Schick. Calorimetry. Polymer Science, 2:793-823, 2012.

[9] V. Delobelle, P. Delobelle, Y. Liu, D. Favier, and H. Louche. Resistance welding of NiTi shape memory alloy tubes. Journal of materials processing Technology, 213:1139-1145, 2013.

[10] Q. Meng, Y. Liu, H. Yang, B. S. Shariat, and T.H. Nam. Functionnally graded NiTi strips prepared by laser surface anneal. Acta Materialia, 60:1658-1668, 2012.

[11] Q. Meng, H. Yang, Y. Liu, T.H. Namb, and D. Favier. Ti-50.8 at.\% $\mathrm{Ni}$ wire with variable mechanical properties created by spatial electrical resistance over-ageing. Journal of Alloys and Compounds, available online. http://dx.doi.org/10.1016/j.jallcom.2012.02.131, 2012.

[12] A. Chrysochoos and H. Louche. An infrared image processing to analyse the calorimetric effects accompanying strain localisation. International Journal of Engineering Science, 38:1759-1788, 2000.

[13] P. Schlosser, H. Louche, D. Favier, and L. Orgéas. Image processing to estimate the heat sources related to phase transformations during tensile tests of NiTi tubes. Strain, 43:260-271, 2007.

[14] H. Louche and A. Chrysochoos. Thermal and dissipative effects accompanying Luders band propagation. Materials Science and Engineering, A307:15-22, 2001.

[15] T. Boulanger, A. Chrysochoos, C. Mabru, and A. Galtier. Calorimetric analysis of dissipative and thermoelastic effects associated with the fa- 
tigue behavior of steels. International Journal of Fatigue, 26:221-229, 2004 .

[16] M.L. Pastor, X. Balandraud, M. Grediac, and J.L. Robert. Applying infrared thermography to study the heating of 2024-T3 aluminium specimens under fatigue loading. Infrared Physics $\mathscr{E}$ Technology, 51:505-515, 2008.

[17] F. Maquin and F. Pierron. Heat dissipation measurements in low stress cyclic loading of metallic materials: From internal friction to microplasticity. Mechanics of Materials, 41:928-942, 2009.

[18] A. Chrysochoos, B. Berthel, F. Latourte, S. Pagano, B. Wattrisse, and B. Weber. Local energy approach to steel fatigue. Strain, 44:327-334, 2008.

[19] A. Saai, H. Louche, L. Tabourot, and H.J. Chang. Experimental and numerical study of the thermo-mechanical behavior of Al bi-crystal in tension using full field measurements and micromechanical modeling. Mechanics of Materials, 42:275-292, 2010.

[20] D. Favier, H. Louche, P. Schlosser, L. Orgéas, P. Vacher, and L. Debove. Homogeneous and heterogeneous deformation mechanisms in an austenitic polycrystalline Ti-50.8 at.\% Ni thin tube under tension : investigation via temperature and strain fields measurements. Acta $\mathrm{Ma}$ terialia, 55(6):530 - 5322, 2007.

[21] P. Schlosser, D. Favier, H. Louche, and L. Orgéas. Experimental characterization of NiTi SMAs thermomechanical behaviour using temperature 
and strain full-field measurements. Advances in Science and Technology (Volume 59), State-of-the-art Research and Application of SMAs Technologies:40-49, September, 2008.

[22] H. Louche, P. Schlosser, D. Favier, and L. Orgéas. Heat source processing for localized deformation with non-constant thermal conductivity. Application to superelastic tensile tests of NiTi shape memory alloys. Experimental mechanics, A:1-16, Avril 2012.

[23] V. Delobelle, D. Favier, and H. Louche. Heat estimation from infrared measurement compared to DSC for austenite to $\mathrm{R}$ phase transformation in a NiTi alloy. Journal of Materials Engineering and Performance, Accepted:DOI 10.1007/s11665-012-0466-y, 2012.

[24] D. Favier and Y. Liu. Restoration by rapid overheating of thermally stabilised martensite of NiTi shape memory alloys. Journal of Alloys and Compounds, 297:114-121, 2000.

[25] Granta. Granta design ces selector software. 20 Trumpington Street, Cambridge UK, 2010.

[26] Matweb. Matweb material property data. Automation Creations, Inc., $1: 1,2012$.

[27] R. Hultgren, R.L. Orr, P.D. Anderson, and K.K. Kelley. Selected values of thermodynamic properties of metals and alloys. John Wiley \& Sons Inc, 1964.

[28] V.D. Sukhanov and Yu N. Tsikovin. Temperature dependence of the 
heat capacity of some titanium alloys. Metallovedenie $i$ termicheskaya obrbotka metallow (traduction en anglais), 6:50-51, 1967.

[29] Y. Combres. Propriétés du titane et de ses alliages. Techniques de l'ingénieur, M 557:1-15, 2012.

[30] U. Heubner. Thermische und elektrische leitfiihigkeit von vanadinlegierungen zwischen 20 und 650C. Journal of Nuclear Materials, 32:88-I 00, 1969.

[31] Y. Terada, K. Ohkubo, K. Nakagawa, T. Mohri, and T. Suzuki. Thermal conductivity of B2-type aluminides and titanides. Intermetallics, $3(5): 347-355,1995$.

[32] C. Zanotti, P. Giuliani, P. Bassani, Z. Zhang, and A. Chrysanthou. Comparison between the thermal properties of fully dense and porous NiTi SMAs. Intermetallics, 18(1):14 - 21, 2010.

[33] V. Delobelle. Contributions à l'étude thermomécanique des alliages à mémoire de forme NiTi et à la réalisation par soudage de matériaux architecturés NiTi. PhD thesis, Université de Grenoble, 2012.

[34] D. Legaie, H. Pron, C. Bissieux, and V. Blain. Thermographic application of black coatings on metals. $9^{\text {th }}$ International Conference on quantitaive InfraRed thermography, 1:1-2, 2008.

[35] V. Delobelle, H. Louche, and D. Favier. Numerical study of the effect of the paint layer used for infrared thermography on the heat sources estimations. QIRT, Submitted to QIRT:1, 2014. 
[36] V. Ayvazyan, J.C. Batsale, and C. Pradere. Simple possibilities of thermal diffusivity estimation for small-sized samples, with a laser pulse heating and infrared cameras. In $10^{\text {th }}$ QIRT, 2010.

[37] C. Pradere, L. Clerjaud, J. C. Batsale, and S. Dilhaire. High speed heterodyne infrared thermography applied to thermal diffusivity identification. Review of scientific instruments, 82:054901, 2011.

[38] H. Kato and K. Sasaki. Avoiding error of determining the martensite finish temperature temperature due to thermal inertia in differential scanning calorimetry: model and experiment of $\mathrm{NiTi}$ and $\mathrm{Cu}-\mathrm{Al}-\mathrm{Ni}$ shape memory alloys. Journal of Materials Science, 47:1399-1400, 2012.

[39] M.G. Faulkner and J.J. Amalraj and A. Bhattacharyya. Experimental determination of thermal and electrical properties of $\mathrm{Ni}-\mathrm{Ti}$ shape memory wires. Smart Materials and Structures, 9:632-639, 2000. 


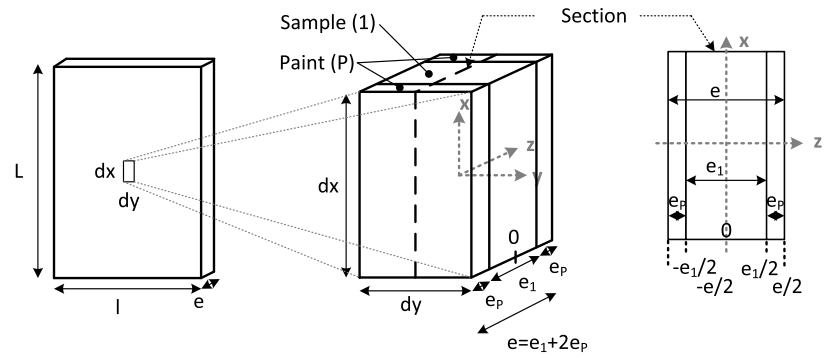

Figure 1: Specimen of thickness $e_{1}$ coated with the two paint layers of thickness $e_{P}$.

a)

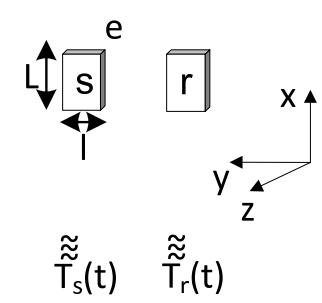

b)

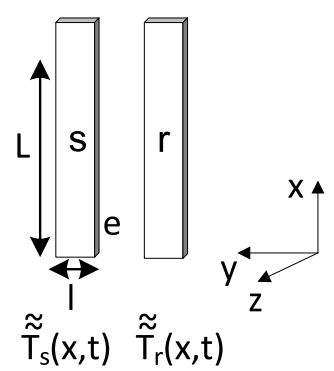

Figure 2: Reference(r) and Studied (s) specimens configurations in (a) homogeneous (0D) and (b) heterogeneous (1D) cooling.
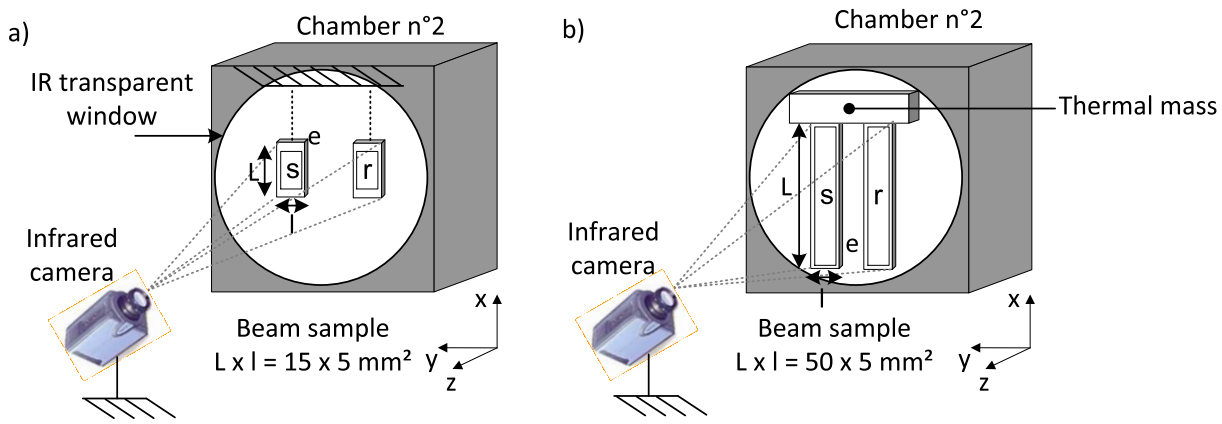

Figure 3: Experimental setup proposed to obtain an (a) homogeneous (0D) and (b) an heterogeneous (1D) cooling. 


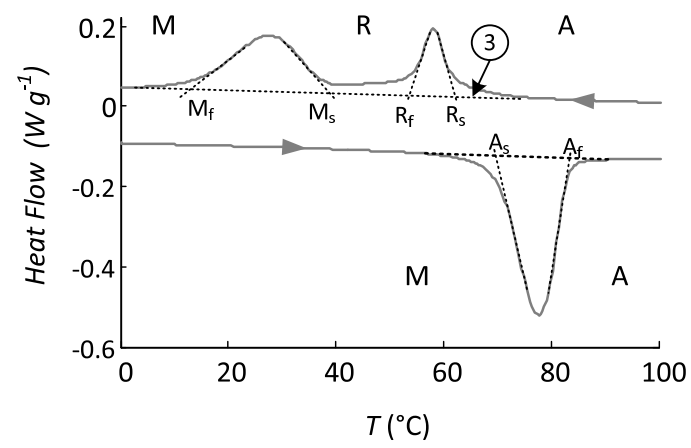

Figure 4: Differential Scanning Calorimetry thermogram of a NiTi DSC specimen.

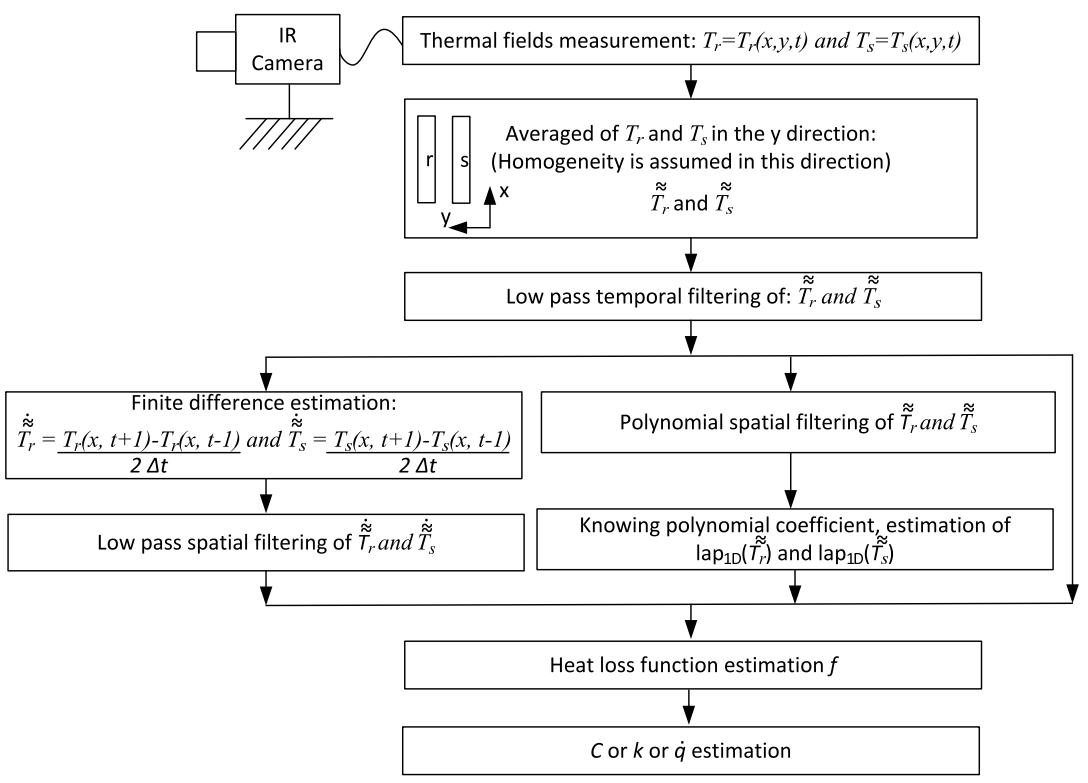

Figure 5: Data processing flow chart. 

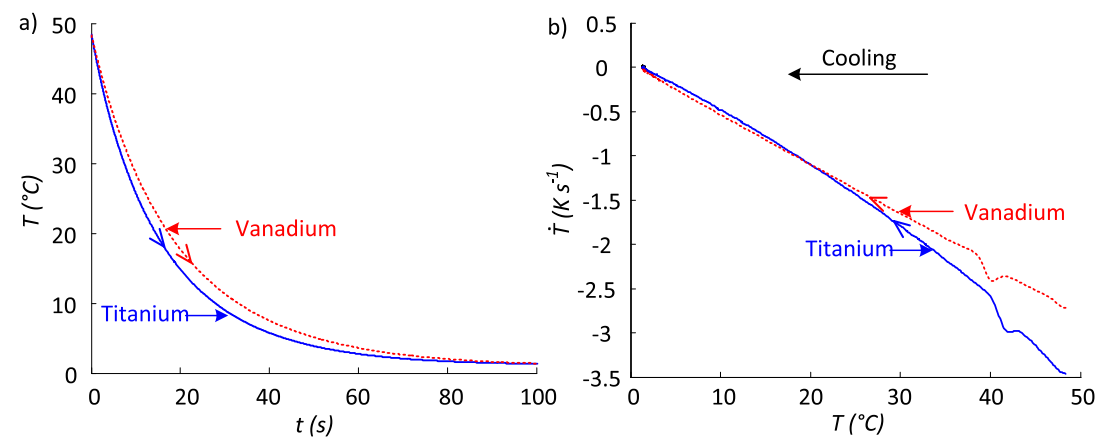

Figure 6: Homogeneous natural cooling of Titanium and Vanadium specimens. a) Temperature versus time and b) Temperature rates versus temperature.

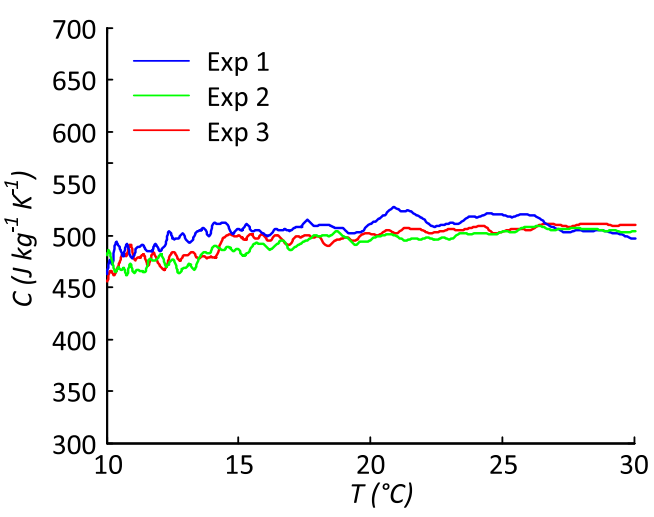

Figure 7: Heat capacity estimation of Vanadium for three distinct experiments. 

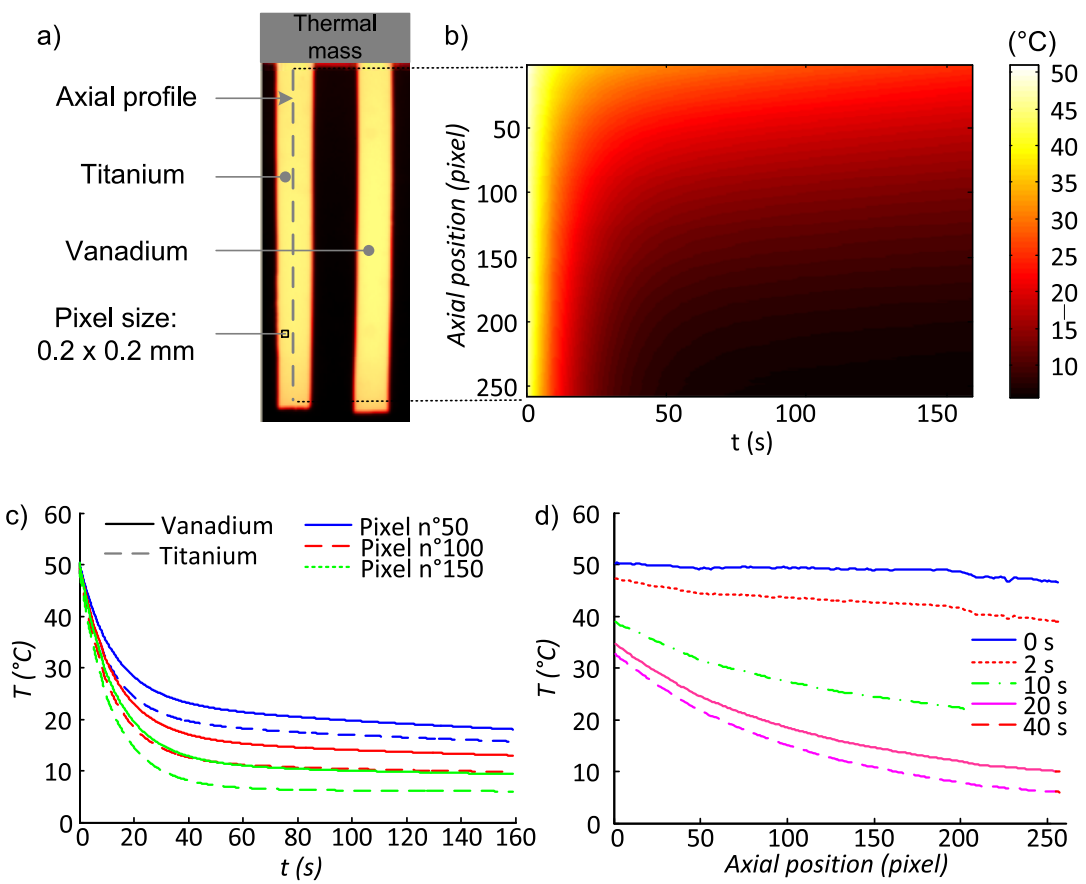

Figure 8: Thermal responses for Titanium and Vanadium specimens in 1D experiment. (a) Thermal image at a given time showing the two specimens. (b) Spatio-temporal representation of temperature along the axial profile plotted in (a) for Titanium specimen. (c) Temporal evolution of the temperature in three different localizations. (d) Axial thermal profiles at different times.

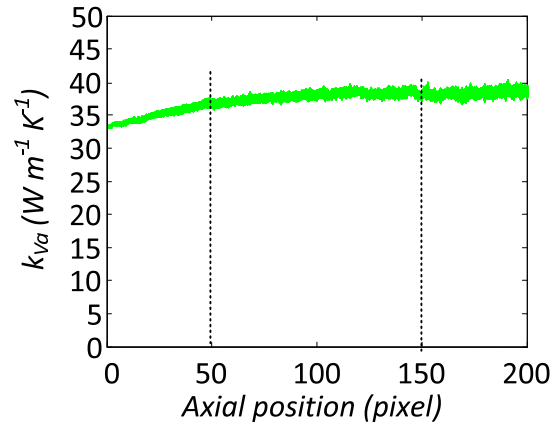

Figure 9: Local thermal conductivity estimation of Vanadium using $k_{T i}=20 \mathrm{Wm}^{-1} \mathrm{~K}^{-1}$. 

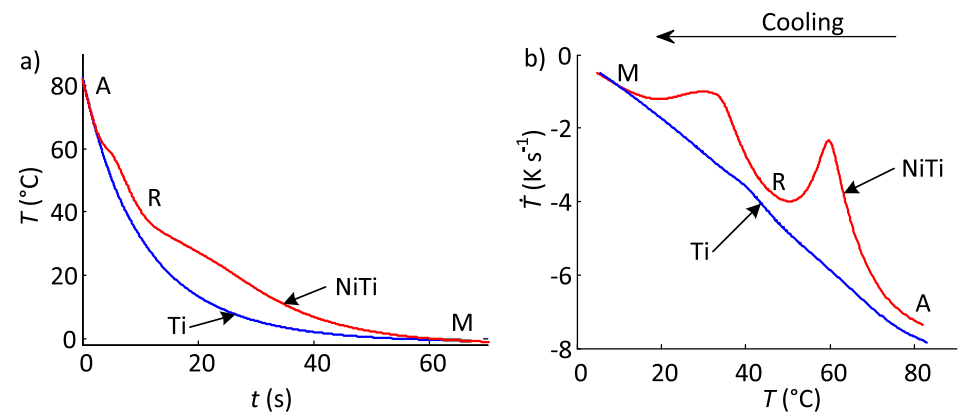

Figure 10: Homogeneous natural cooling of Titanium and NiTi specimens. a) Temperature versus time and b) Temperature rate versus temperature.
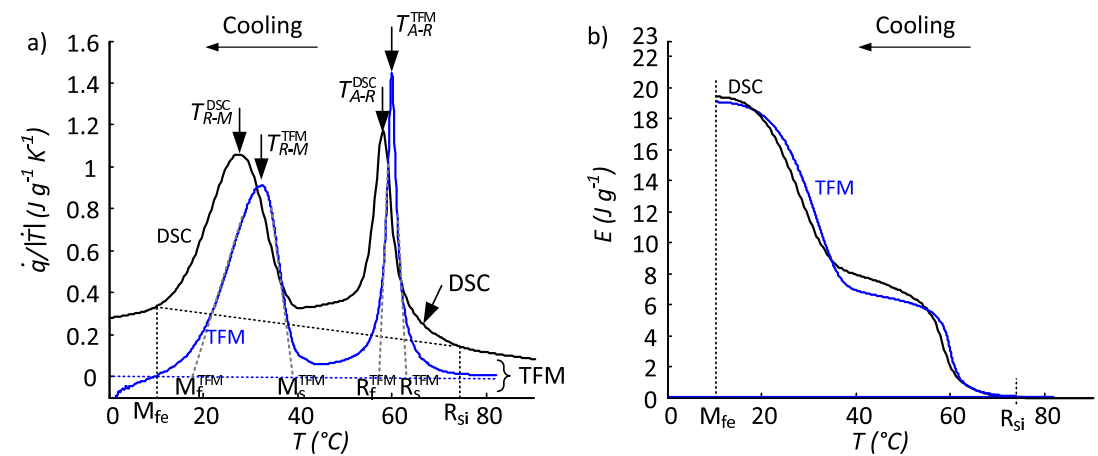

Figure 11: Estimation of transition heat - homogeneous natural cooling of the NiTi specimen. (a) Ratio $\frac{\dot{q}}{|\dot{T}|}$ and (b) energy evolution, measured by DSC and by TFM techniques. 

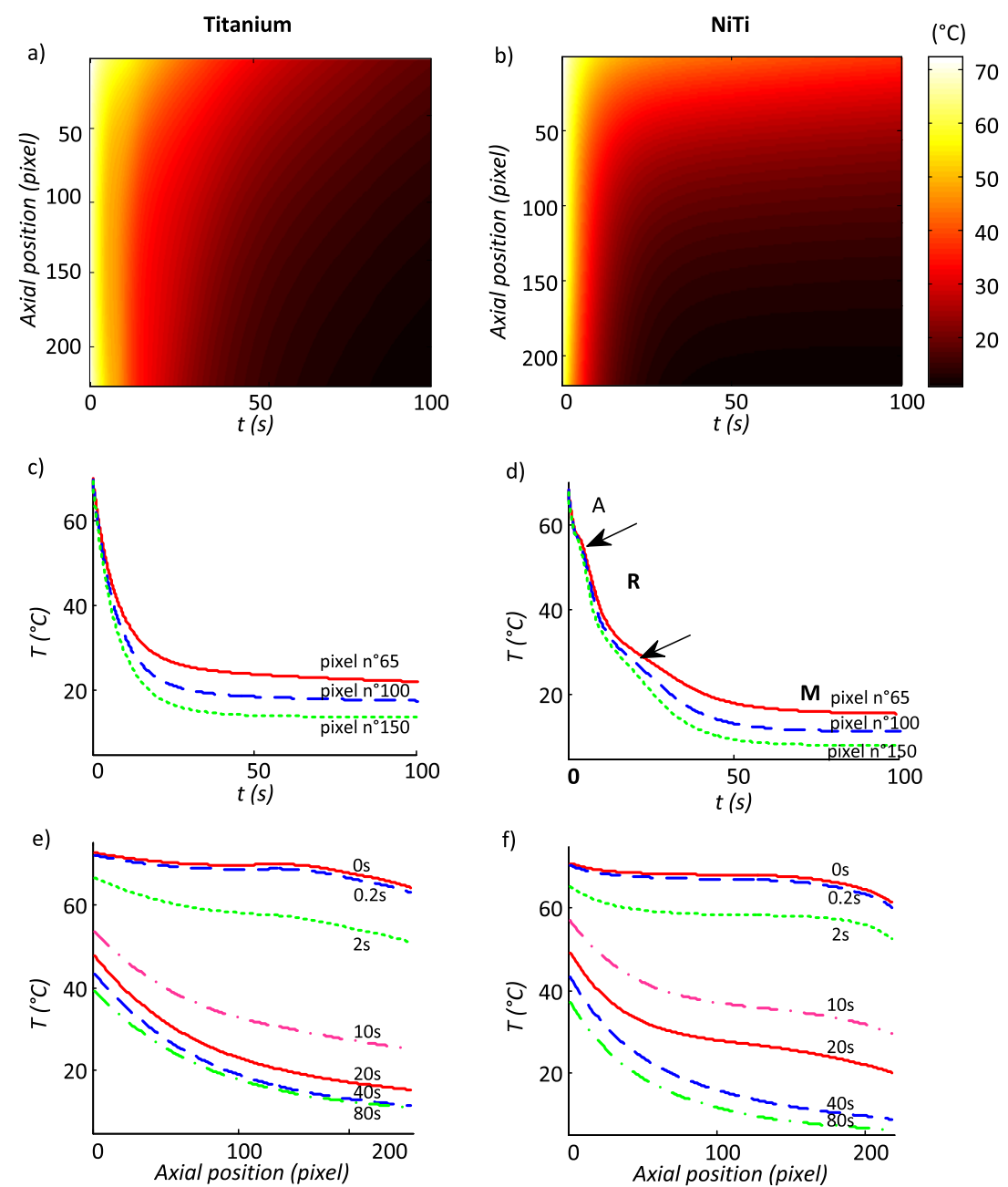

Figure 12: Thermal responses for Titanium and NiTi specimens in 1D experiment. Spatiotemporal representation of temperature along the axial profile for (a) Titanium and (b) NiTi specimen. Temporal evolution of the temperature in three different localizations for (c) Titanium and (d) NiTi specimen. Axial thermal profiles at different times for (e) Titanium and (f) NiTi specimen. 

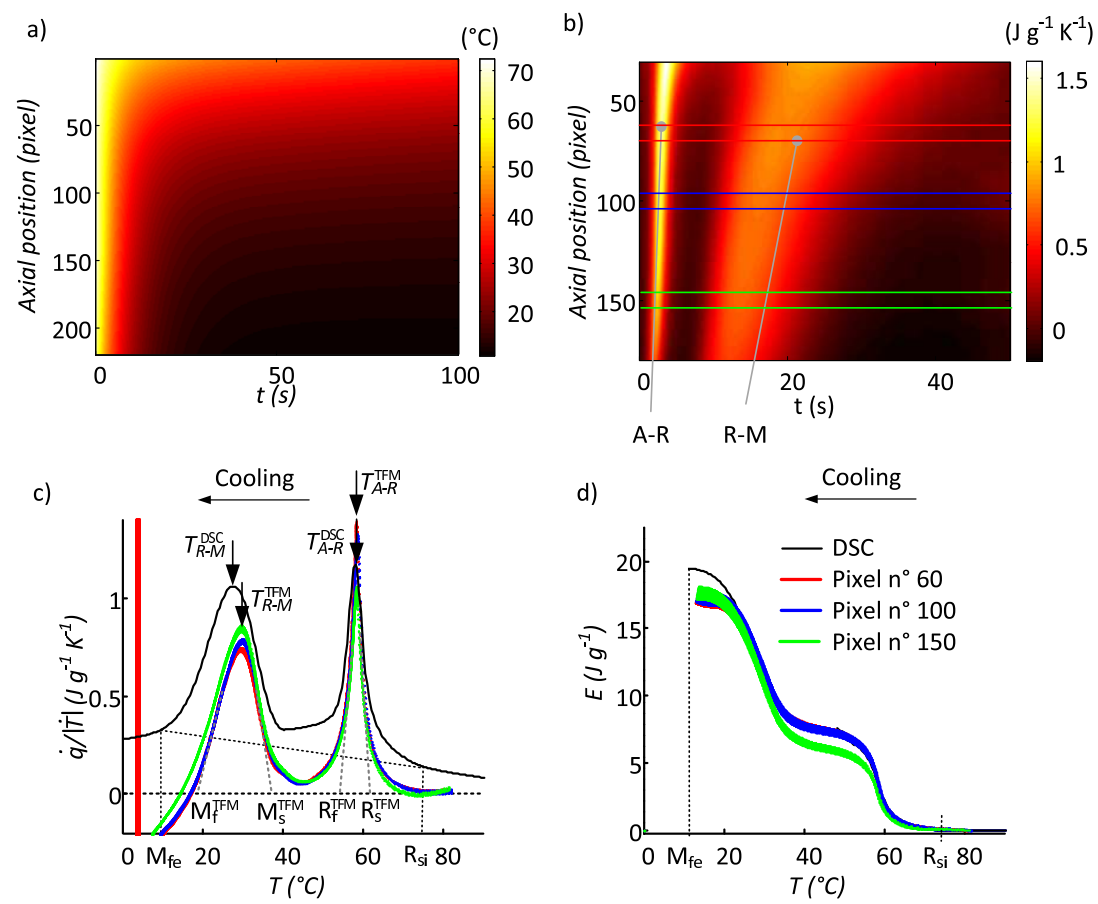

Figure 13: Estimation of transition heat - heterogeneous natural cooling of the NiTi specimen. (a) Spatio-temporal representation of temperature along the axial profile for $\mathrm{NiTi}$ specimen. (b) Spatio-temporal representation of ratio $\frac{\dot{q}}{|T|}$ evaluated with TFM technique. (c) Comparison of the ratio calculated from DSC and TFM techniques and (d) Energy evolution during cooling for pixels 60 to 70,95 to 105 and 145 to 155 .

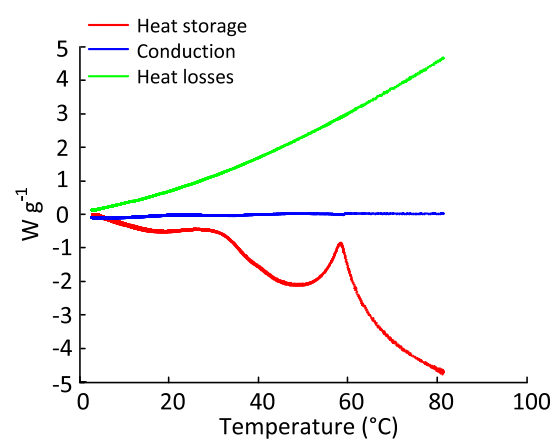

Figure 14: Evolution, with the temperature, of the terms involved in the massic heat sources estimation for NiTi sample (equation 19) for pixels 60 to 70. 